\title{
J.H. SCHNEIBEL
}

Metals and Ceramics Division, Oak Ridge National Laboratory, Oak Ridge, TN 37831-6115, schneibeljh@ornl.gov

\section{ABSTRACT}

Iron aluminides with the $\mathrm{B} 2$ structure are highly oxidation and corrosion resistant. They are thermodynamically compatible with a wide range of ceramics such as $\mathrm{TiC}, \mathrm{WC}, \mathrm{TiB}_{2}$, and $\mathrm{Z}_{\mathrm{rB}}$. In addition, liquid iron aluminides wet these ceramics very well. Therefore, FeAl/ceramic composites may be produced by techniques such as liquid phase sintering of powder mixtures, or pressureless melt infiltration of ceramic powders with liquid FeAl. These techniques, the resulting microstructures, and their advantages as well as limitations are described. Iron aluminide composites can be very strong. Room temperature flexure strengths as high as $1.8 \mathrm{GPa}$ have been observed for FeAl/WC. Substantial gains in strength at elevated temperatures $(1073 \mathrm{~K})$ have also been demonstrated. Above 40 vol.\% WC the room temperature flexure strength becomes flawlimited. This is thought to be due to processing flaws and limited interfacial strength. The fracture toughness of FeAI/WC is unexpectedly high and follows a rule of mixtures. Interestingly, sufficiently thin $(<1 \mu \mathrm{m}) \mathrm{FeAl}$ ligaments between adjacent WC particles fracture not by cleavage, but in a ductile manner. For these thin ligaments the dislocation pile-ups formed during deformation are not long enough to nucleate cleavage fracture, and their fracture mode is therefore ductile. For several reasons, this brittle-to-ductile size transition does not improve the fracture toughness of the composites significantly. However, since no cleavage cracks are nucleated in sufficiently thin FeAl ligaments, slow crack growth due to ambient water vapor does not occur. Therefore, as compared to monolithic iron aluminides, environmental embrittlement is dramatically reduced in iron aluminide composites.

\section{INTRODUCTION}

As described in several recent symposium proceedings, iron aluminides with the B2 crystal structure exhibit excellent resistance against oxidation and corrosion [1,2]. However, they tend to be difficult to process. For example, fabrication of iron aluminide sheets involves roll bonding of powders followed by repeated annealing/sintering and cold rolling steps [3]. Also, the mechanical properties need improvement. Room temperature ductilites are typically limited to $10 \%$, although values as high as $20 \%$ have been reported $[1,4]$. Environmental embrittlement due to water vapor is, at least in part. the reason for the low ductilities [5-8]. Another shortcoming of iron aluminides is their poor creep strength at elevated temperatures such as $1000 \mathrm{~K}$ [9].

There are different approaches to improve the properties of iron aluminides. One of them which will be examined here, is based on iron aluminide composites. The focus will be on $W_{t h}$ aluminide composites containing non-oxide ceramics such as $\mathrm{TiC}, \mathrm{WC}$, and $\mathrm{TiB}_{2}$. In recent years, iron aluminide composites containing oxides have also been investigated [10]. They are howevernot as advanced as the non-oxide composites. It should also be pointed out that another important class of intermetallic matrix composites is based on $\mathrm{Ni}_{3} \mathrm{Al}$ [11-13].

As we shall see, processing of iron aluminide composites by liquid phase sintering is simple. Iron aluminide composites are expected to be strong at ambient and elevated temperatures. On the other hand, composites exhibit generally lower ductilities and fracture toughnesses than their monolithic counterparts. Since iron aluminides tend to have fairly low fracture toughnesses on the order of $50 \mathrm{MPa} \mathrm{m} / 2$ [1] one might expect their composites to be quite brittle. Surprisingly, this is not the case. In fact, FeAl/WC composites have fracture toughnesses comparable to those of WC/Co hard metals with similar WC volume fractions. The reasons for this are not completely understood. However, one factor which may play a role is the brittle-to-ductile size transition observed for sufficiently thin $(<1 \mu \mathrm{m})$ iron aluminide ligaments. This brittle-to-ductile transition may be of general importance as it appears to occur in other composite systems as well. The concept of the brittle-ductile size transition also suggests ways in which the water-vapor embrittlement of iron aluminides can be suppressed.

\footnotetext{
"The submitted manuscript has been authored by a contractor of the U.S. Government under contract No. DE.ACO5. 96OR22464. Accordingly. the U.S. Government retains a nonexciusive, royalty free license to publish or reproduce the published form of this contribution. or allow others to do so, for U.S. Government purposes
} 


\section{DISCLAIMER}

This report was prepared as an account of work sponsored by an agency of the United States Government. Neither the United States Government nor any agency thereof, nor any of their employees, make any warranty, express or implied, or assumes any legal liability or responsibility for the accuracy, completeness, or usefuiness of any information, apparatus, product, or process disclosed, or represents that its use would not infringe privately owned rights. Reference herein to any specific commercial product, process, or service by trade name, trademark, manufacturer, or otherwise does not necessarily constitute or imply its endorsement, recommendation, or favoring by the United States Government or any agency thereof. The views and opinions of authors expressed herein do not necessarily state or reflect those of the United States Government or any agency thereof. 


\section{DISCLAIMER}

Portions of this document may be illegible in electronic image products. Images are produced from the best available original document. 


\section{EXPERIMENTAL PROCEDURE}

Iron aluminide composites were fabricated from prealloyed $\mathrm{Fe}-40$ at. $\% \mathrm{Al}$ powders and from $\mathrm{TiC}, \mathrm{WC}$, or $\mathrm{TiB}$, powders. The $\mathrm{Fe}-40$ at. \% Al powder will for simplicity be referred to as $\mathrm{FeAl}$. The $\mathrm{FeAl}$ and $\mathrm{TiB}_{2}$ powders were -325 mesh $(<45 \mu \mathrm{m})$, the $\mathrm{WC}$ powder size was $5-10 \mu \mathrm{m}$, and the TiC powder size was on the order of $3 \mu \mathrm{m}$. Processing was carried out in two different ways, either by conventional liquid phase sintering, or by pressureless melt infiltration (a special case of liquid phase sintering). For brevity, the conventional liquid phase sintering will be referred to as "liquid phase sintering." It was carried out by mixing appropriate quantities of powders, placing them in an alumina boat, and heating in vacuum (typ. $10^{-3} \mathrm{~Pa}$ ) above the melting point of $\mathrm{FeAl}$, typically to $1723 \mathrm{~K}$ [14]. After holding for times ranging from 15 to 60 minutes, the specimens were furnace cooled. The alumina boat in FIG01 was initially filled to its top with a mixture of FeAl and $\mathrm{TiB}_{2}$ powders. As shown, liquid phase sintering resulted in pronounced shrinkage resulting in near theoretical density.

The second processing technique, pressureless melt infiltration, or more shortly, melt infiltration, is illustrated in FIG02. FeAl powder was placed on top of a cold-pressed TiC coupon. During heating in vacuum, the TiC sintered partially. At some point during the heating-up, the iron aluminide melted. Since liquid iron aluminide wets $\mathrm{TiC}$ extremely well, it infiltrated the TiC coupon, thus eliminating its porosity almost completely, and creating a strong composite. While this technique worked very well for $\mathrm{TiC}$, it did require modification for ceramics such as WC or $\mathrm{TiB}_{2}$. WC and $\mathrm{TiB}_{2}$ had not sintered noticeably by the time the iron aluminide became liquid. Presumably because of the poor mechanical strength of the $\mathrm{WC}$ or $\mathrm{TiB}_{2}$ coupons, infiltration resulted in cracking. In order to avoid this problem a small amount of a sintering aid, such as Co in the case of $\mathrm{WC}$, or $\mathrm{Fe}$ or $\mathrm{Ni}$ in the case of $\mathrm{TiB}_{2}$, was added to the ceramic powder prior to pressing and infiltration. In this way, partial sintering prior to infiltration was achieved. Another
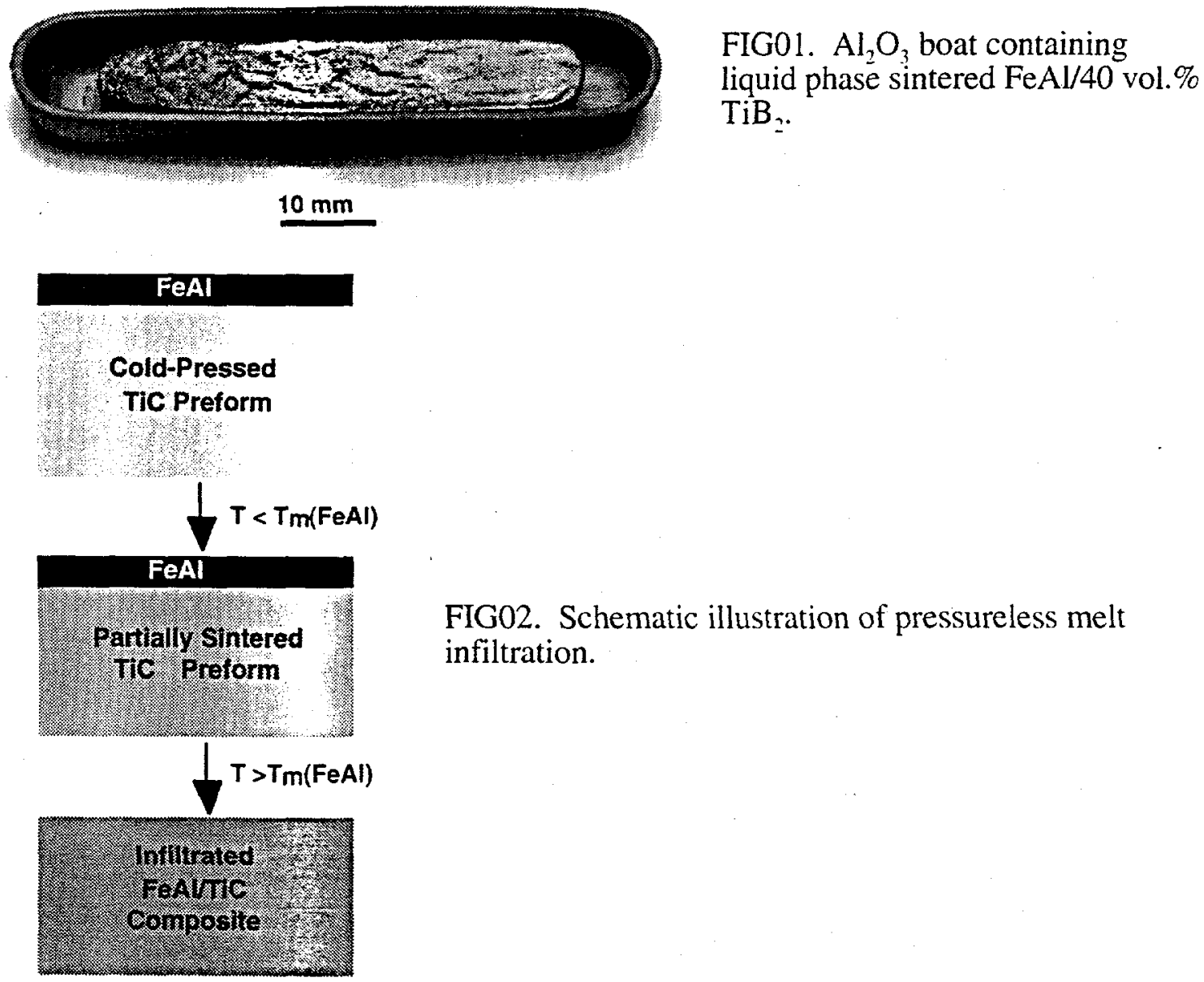

FIG02. Schematic illustration of pressureless melt infiltration. 
way to process iron aluminde composites consists of hot pressing of powder mixtures. This processing route, which will not be further discussed here, has been successfully employed by Inoue $[15,16]$ to fabricate many different iron aluminide composites.

The microstructure of the composites was evaluated by conventional metallographic techniques such as optical microscopy, scanning electron microscopy (SEM), and energy dispersive spectroscopy (EDS). The strength of the composites was evaluated by 3-point flexure tests. The specimen cross sections were $3 \times 4 \mathrm{~mm}$, and the span $20 \mathrm{~mm}$. Stresses $\sigma$ and strains $\varepsilon$ were calculated from the linear elastic relationships $\sigma=1.5 \mathrm{~L} \mathrm{P} / \mathrm{wt}^{2}$ and $\varepsilon=6 \mathrm{t} l / \mathrm{L}^{2}$, where $\mathrm{L}$ is the span, $\mathrm{P}$ the applied load. $\mathrm{w}$ the specimen width, $\mathrm{t}$ the specimen height, and $l$ the displacement of the cross head of the testing machine. As described in previous work [16] fracture toughnesses were evaluated by the controlled breaking of chevron-notched flexure bars in 3-point bending and determining the dissipated energy $W$. The fracture toughness $K_{0}$ was evaluated as $\left[(\mathrm{W} / \mathrm{A}) \mathrm{E}^{\prime}\right]^{1 / 2}$, where $E$ ' is the plane strain Young's modulus and A the area swept out by the crack. The Young's modulus was obtained from Ravichandran's equation describing the modulus of composites consisting of phases with different elastic moduli [eqn. (8) in Ref. 17].

\section{RESULTS AND DISCUSSION}

\section{Processing and microstructures}

The optical micrograph in FIG03 illustrates the microstructure of a FeAl/40 vol.\% $\mathrm{TiB}_{2}$ composite. This particular composite was first liquid phase sintered for $0.5 \mathrm{~h}$ at $1723 \mathrm{~K}$. The specimen corresponding to this particular micrograph was in addition hot isostatically pressed (HIPed) to remove residual porosity as far as possible. The micrograph ilustrates the excellent wetting of $\mathrm{TiB}_{2}$ by $\mathrm{FeAl}$, the absence of chemical reactions, and a fairly homogeneous distribution of the $\mathrm{TiB}_{2}$ particles. Generally, for 40 vol.\% ceramic loading, liquid phase sintering without subsequent hot isostatic pressing (HIPing) resulted in $98-99 \%$ of the theoretical density. FIG04 shows an SEM micrograph of a polished section of a liquid phase sintered FeAl/60 vol.\% WC composite. Although this particular micrograph showed virtually no porosity, pores were occasionally seen in other parts of the specimen. Sometimes, these pores were associated with non-wetting oxide inclusions [18]. In other cases, substantial volume fractions of large $(20 \mu \mathrm{m}$ diameter) pores were seen [18]. The reason for the porosity is illustrated in FIG05. Once the FeAl melts, it infiltrates the surrounding WC particles, thus leaving a hole behind. To avoid this problem it would be desirable to have an $\mathrm{FeAl}$ powder size equal to or smaller than the WC particle size. However, this would result in a dramatically increased surface-to-volume ratio of the FeAl powder and thus encourage the formation of non-wetting oxides.

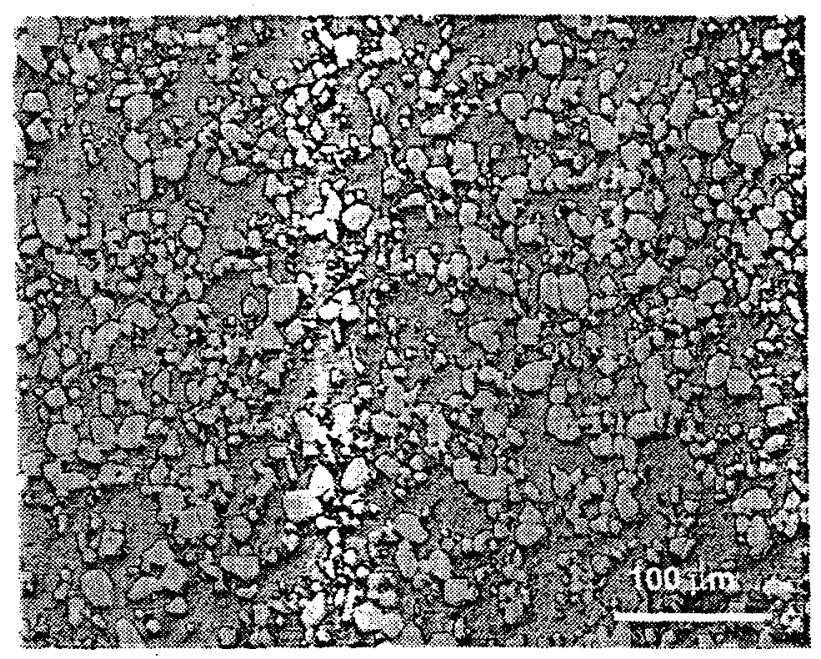

FIG03. Optical micrograph of polished section of $\mathrm{FeAl} / 40$ vol. $\% \mathrm{TiB}_{2}$ composite liquid phase sintered for $0.5 \mathrm{~h}$ at $1723 \mathrm{~K}$ and hot isostatically pressed for $0.5 \mathrm{~h}$ at $1373 \mathrm{~K}$ and $200 \mathrm{MPa}$.

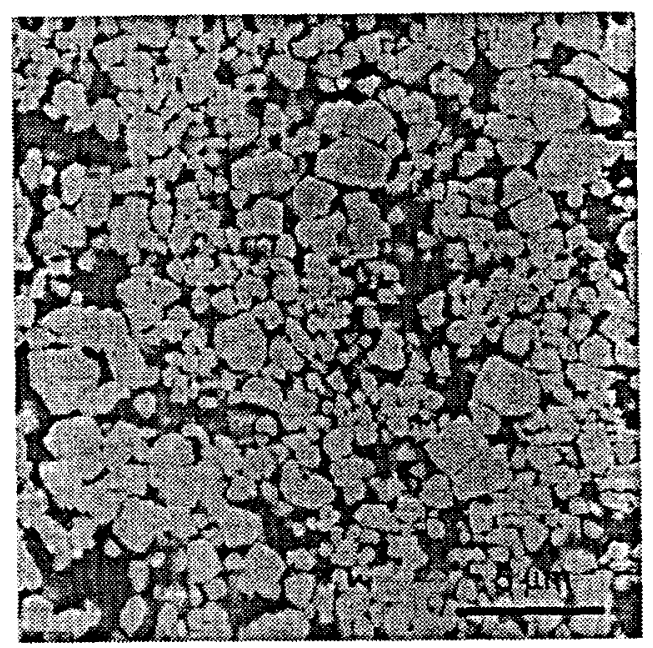

FIG04. SEM micrograph of polished section of liquid phase sintered $\mathrm{FeAl} / 60$ vol.\% WC. 

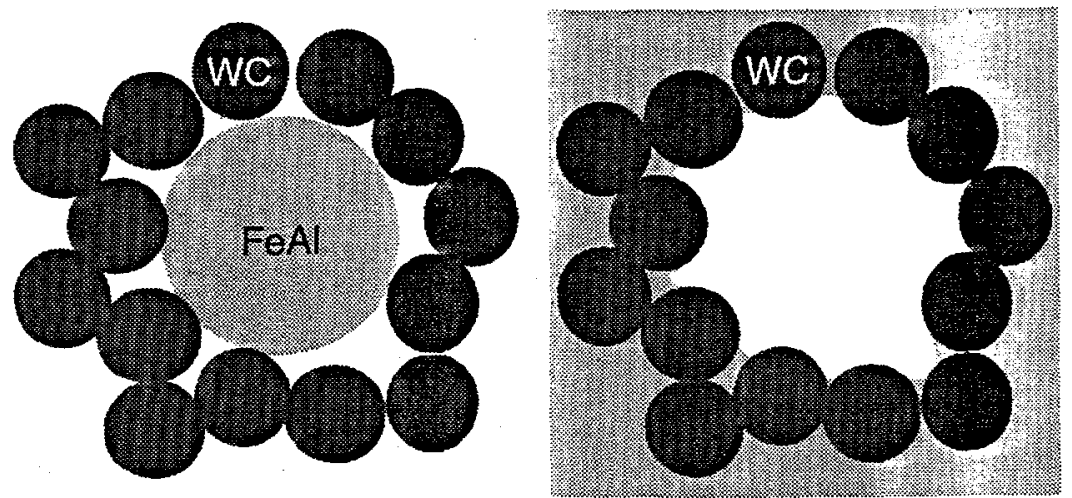

FIG05. Schematic illustration

of pore formation during

liquid phase sintering.

The pressureless melt infiltration technique developed by Subramanian et al. $[19,20]$ avoids some of the problems encountered in conventional liquid phase sintering. In this technique, the cold-pressed ceramic coupons to be infiltrated do not contain $\mathrm{FeAl}$ powder particles, and therefore this particular source of porosity is absent. Since the iron aluminide infiltrates the preform in the form of a molten front, it will also not oxidize as readily as when a mixture of ceramic and iron aluminide powders is heated up slowly. Melt infiltration alleviates also a common problem encountered in the liquid phase sintering of practically all composites with the exception of WC/Co, namely, the difficulty of obtaining a composite with a high ceramic volume fraction on the order of 80 or 90 vol. $\%$, while maintaining close-to-theoretical density. While liquid Co at $1773 \mathrm{~K}$ dissolves approximately 15 mole \% WC [21], liquid FeAl at 1723 dissolves only on the order of 1 $\%$ or less of $\mathrm{WC}$ or $\mathrm{TiC}[22]$. In melt infiltration, the low solubility of the ceramic in the iron aluminide is to some extent offset by particle rearrangement during the infiltration. This is illustrated in FIG06, in which the densification after infiltration of previously sintered $\mathrm{TiC}$ coupons with 70 and $80 \mathrm{vol} . \%$ of theoretical density has been determined. The figure shows that the infiltration of a $70 \%$ dense TiC coupon (containing 30 vol. $\%$ porosity) with 10 vol. $\% \mathrm{FeAl}$ results in a $97 \%$ dense composite. In view of the low solubility of $\mathrm{TiC}$ in liquid $\mathrm{FeAl}$ it is unlikely that the pronounced reduction in porosity is caused exclusively by a dissolution-reprecipitation mechanism. It is instead thought that extensive particle rearrangement during infiltration is instrumental in reducing the porosity. This notion is supported by the following finding: if particle rearrangement is inhibited by excessive sintering of the ceramic preform prior to infiltration ( $80 \%$ initial density in FIG06), the final density of the composite is not as high as for the case of $70 \%$ initial density. With melt infiltration and appropriate processing conditions, theoretical densities approaching $100 \%$ may be obtained for ceramic volume fractions up to $80 \%$. In contrast, conventional liquid phase sintering results in extensive porosity for ceramic volume fractions exceeding $60 \%$.

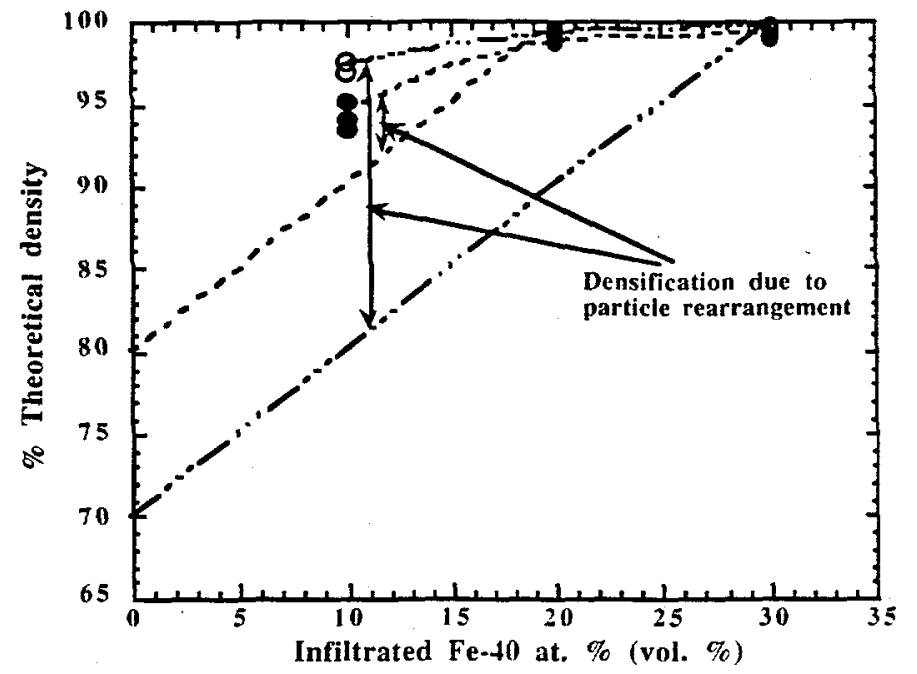

FIG06. The determination of the percentages of theoretical density of infiltrated $\mathrm{TiC}$ compacts suggests that particle rearrangement is important for densification. 
While significant progress has been made in the processing of iron aluminide composites, significant improvements are still possible and needed. This will become more obvious once we examine the mechanical properties of these materials.

\section{Flexure strength and fracture toughness}

FIG07 shows the substantial increase in the high temperature strength of iron aluminide composites as the WC volume fraction is increased [18]. At the test temperature of $1073 \mathrm{~K}$, the 3point flexure specimens showed distinct ductility as illustrated by the picture of a tested FeAl/60 vol.\% WC specimen. Also, examination of a metallographic section of this specimen did not reveal any cavitation in its tensile stress region.

FIG08 compares the fracture (or yield) strengths of FeAl/WC composites as a function of the WC volume fraction. Up to about 40 vol.\% WC, the strengths in tension and compression are quite similar. Above $40 \mathrm{vol} . \% \mathrm{WC}$, the 3-point flexure strengths become lower than the compressive strengths. This suggests that the tensile fracture strength is now governed by flaws which initiate fracture well before the strength in the absence of such flaws would be reached. The microstructures discussed earlier have shown clearly that such flaws can be present. The detrimental effects of the flaws on fracture may be reduced by improving the mechanical properties of the iron aluminide matrix or by improving the resistance to interfacial debonding. FIG09 shows the room temperature 3-point flexure strengths of a $\mathrm{FeAl} / 60 \mathrm{vol} . \% \mathrm{WC}$ composite [18]. In one case, the composite was first liquid phase sintered and then HIPed at $1373 \mathrm{~K}$ and $200 \mathrm{MPa}$, followed by cooling in less than an hour. The flexure strengths showed substantial scatter indicating a wide distribution of weakening flaws. Annealing for 1 day at $773 \mathrm{~K}$, which reduced the thermal vacancy concentration resulting from the cool-down after HIPing [4], reduced the scatter in the flexure strengths substantially. This result is rationalized by the improved ductility of the iron aluminide matrix due to removal of vacancies by annealing.

In the $\mathrm{FeAl} / \mathrm{TiB}_{2}$ system, an attempt was made to influence the strength of the interfacial bonding [23]. Coupons containing additions of either Ti or B were liquid phase sintered, and their flexure strengths and fracture toughnesses were determined. Unfortunately, the elemental alloying additions increased the scatter in the flexure strengths. However, for composites containing 0.2 or 0.5 at. \% additional boron, the maximum measured strengths were slightly higher than those for unalloyed $\mathrm{FeAl} / \mathrm{TiB}_{2}$. A similar result was obtained for the fracture toughnesses. These results are not conclusive because in the process of alloying the $\mathrm{FeAl}$ with $\mathrm{B}$ or Ti the strength limiting flaws were changed. However, they suggest the possibility that the mechanical properties of iron aluminide composites may be improved by changing the interfacial properties.
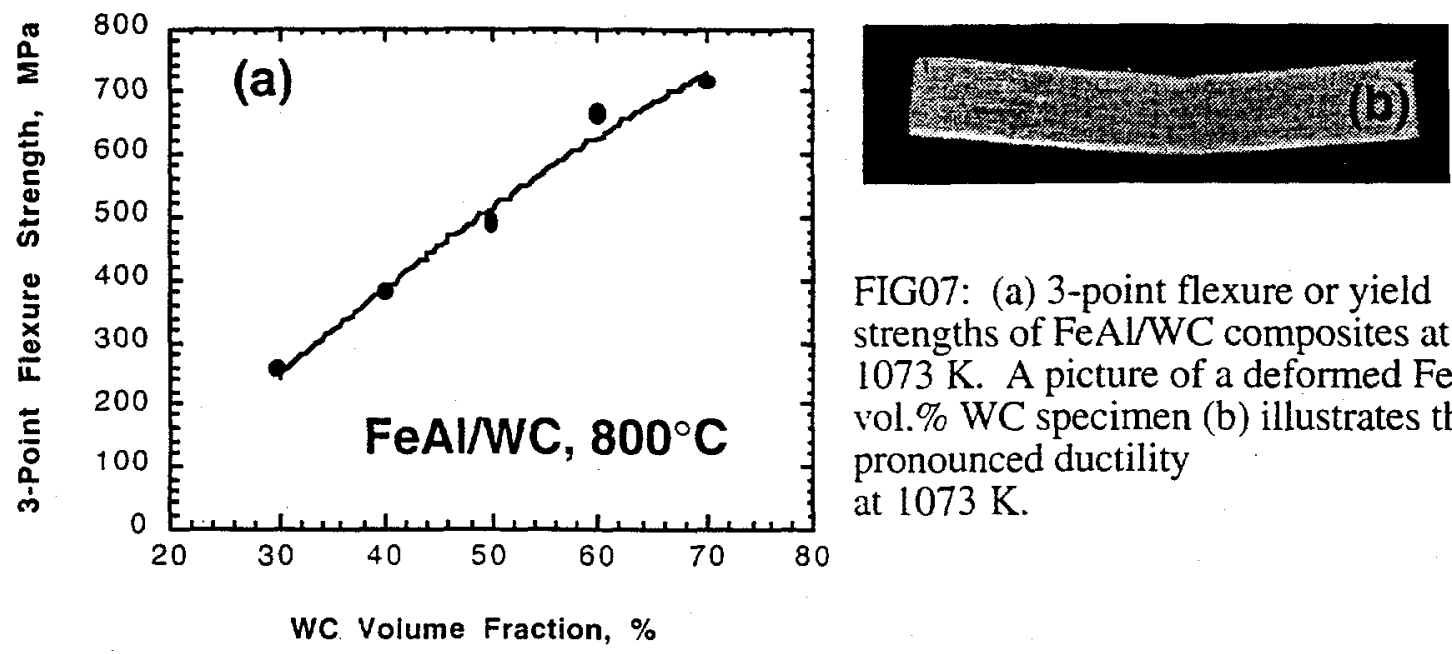

FIG07: (a) 3-point flexure or yield strengths of $\mathrm{FeAl} / \mathrm{WC}$ composites at $1073 \mathrm{~K}$. A picture of a deformed $\mathrm{FeAl} / 60$ vol.\% WC specimen (b) illustrates the pronounced ductility at $1073 \mathrm{~K}$. 
Fe-40 at. $\%$ Al/WC, Room Temperature
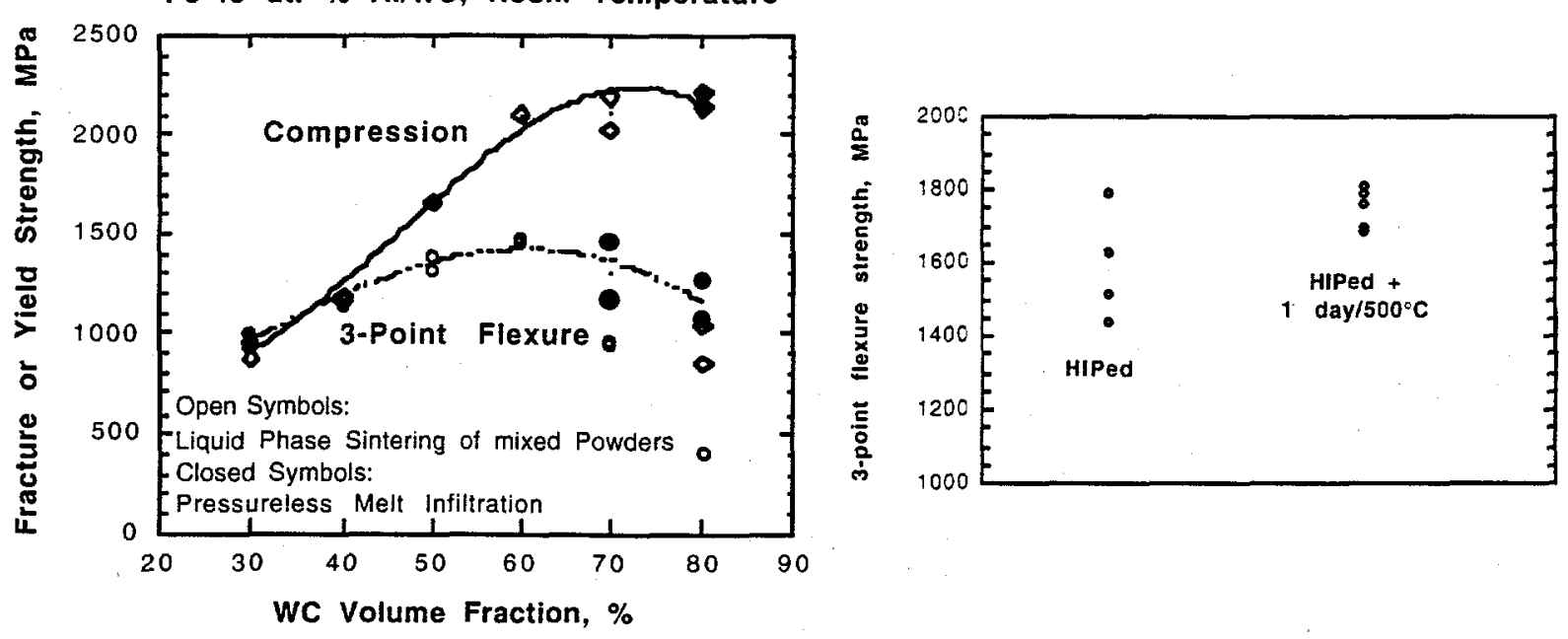

FIG08. Fracture or yield stresses, of FeAl/WC composites in tension (3-point bending) and compression.

FIG09. Effect of low-temperature annealing ( 1 day at $773 \mathrm{~K}$ ) on the 3 -point flexure strength of $\mathrm{FeAl} / 60 \mathrm{vol} . \%$ WC.

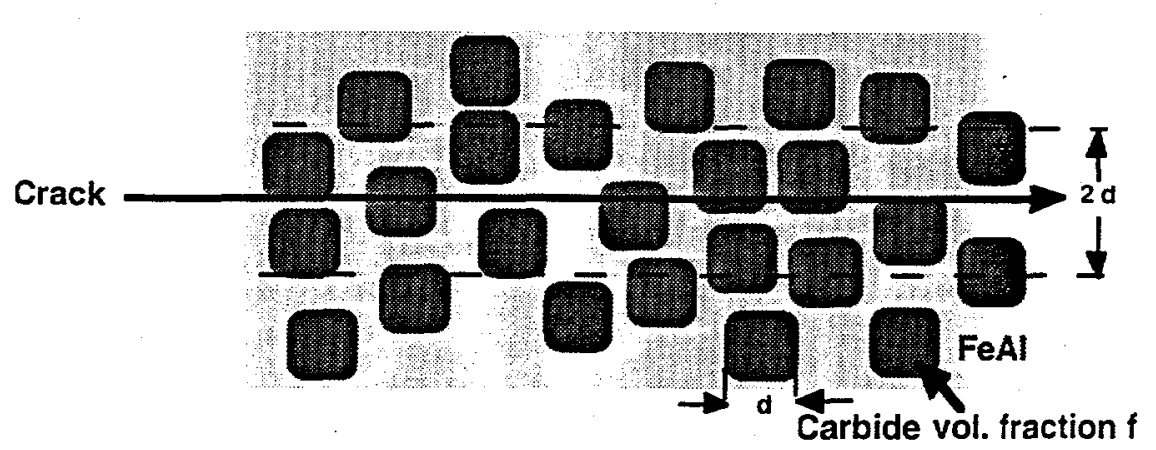

FIG10. Illustration of a crack propagating through a composite.

\section{Modeling of fracture toughness}

The modeling of the fracture toughness of composites over a wide range of particle volume fractions is not well understood. FIG10 illustrates the modeling for a high ceramic volume fraction. It shows a crack propagating through a composite. It is assumed that the ductile FeAl material contributing to the toughening deforms within a distance $d$ (where $d$ is the particle size) from either side of the crack. If the area swept out by the advancing crack is $\mathrm{A}$, the volume of FeAl ligaments is:

$$
V=(1-f)(2 d) A,
$$

where $\mathrm{f}$ is the particle volume fraction. Neglecting for simplicity the contribution from the ceramic phase, the absorbed energy is

$$
\mathrm{W}=\sigma_{\mathrm{av}} \varepsilon_{\mathrm{f}} \mathrm{V},
$$

where $\sigma_{\mathrm{av}}$ is the average flow stress of the ligaments and $\varepsilon_{\mathrm{i}}$ their strain to fracture. The fracture toughness $\mathrm{K}_{\mathrm{Q}}$ is given in terms of the crack growth resistance $\mathrm{G}=\mathrm{W} / \mathrm{A}$ :

$$
K_{Q}=\left(G E^{\prime}\right)^{1 / 2} \text {, }
$$

where $E^{\prime}$ is the plane strain Young's modulus $E /\left(1-v^{2}\right)$. Depending on the WC volume fraction. $E$ varies from 180 to $650 \mathrm{GPa}$. The fracture toughness values calculated with typical values of 
$\sigma_{\mathrm{av}}=500 \mathrm{MPa}, \varepsilon_{\mathrm{f}}=0.2$, and $\mathrm{d}=10 \mu \mathrm{m}$ are indicated by a broken line in FIG11. For large WC volume fractions, the correct trend is predicted. For WC volume fractions smaller than about $70 \%$, eqn. (3) breaks down, presumably because the assumption that the crack tip plastic zone size is on the order of the particle diameter becomes invalid. Assuming a fracture toughness of $50 \mathrm{MPa} \mathrm{m}{ }^{1 / 2}$ [1] for $\mathrm{Fe}-40$ at. $\mathrm{Al}$, the measured fracture toughnesses are reasonably well described by a straight line suggesting a rule of mixtures.

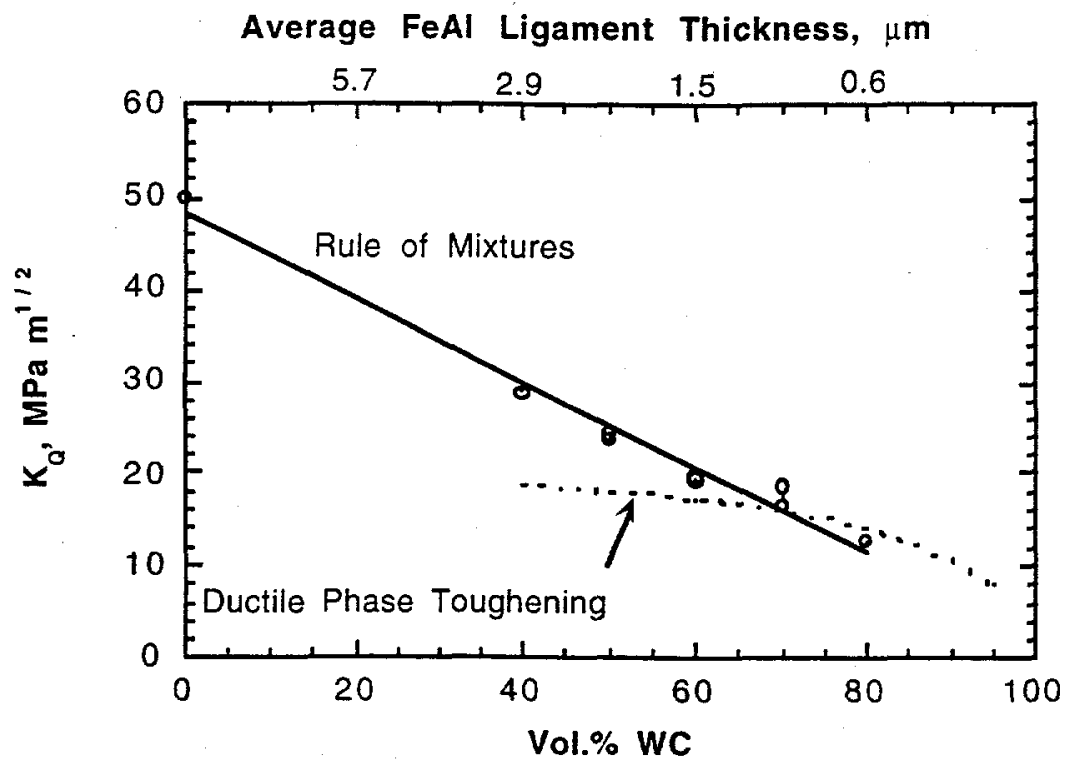

FIG1 1. The fracture toughnesses of FeAl/WC depends linearly on the WC volume fraction. The results of the simple model for ductile phase toughening are indicated by a broken line.

\section{Ductile-brittle transition size}

Inspection of FIG 11 shows that the fracture toughnesses for 70 and 80 vol.\% of WC are slightl;y above the fitted line, while the other values are below. Room temperature fracture surfaces show cleavage in the thicker $(>1 \mu \mathrm{m})$ iron aluminide ligaments, while thin iron aluminide ligaments $(<1$ $\mu \mathrm{m}$ ) tend to fracture in a ductile manner [14]. A similar observation is made for FeAlTiC (FIG 12). These observations suggest the existence of a brittle-to-ductile size transition [24]. In FIG 11, as the fracture toughness decreases with increasing WC volume fraction, there is a tentative plateau between 60 and 70 vol.\%. For reference, the average FeAl ligament sizes estimated by $d\left(f^{1 / 3}-1\right)$ are indicated. Due to their high ductility, sufficently thin ligaments might be the reason for the plateau by providing an additional contribution to the fracture toughness. Because of the wide distribution of ligament thicknesses, and since, for a given fracture mode, toughening tends to decrease with decreasing ligament thickness, this additional toughening is not easy to verify. However, while evidence for this additional contribution to the fracture toughness is tenuous, the evidence for the ductile-to-brittle size transition is not. FIG13 shows the fracture mode as a function of the FeAl ligament size for a FeAl/70 vol.\% TiC composite. Clearly, thin $(<1$ $\mu \mathrm{m})$ ligaments fracture in a ductile manner. There are good reasons to expect such a ductile-tobrittle size transition. These are sketched in FIG14. In agreement with FIG12, we assume that debonding occurs between the $\mathrm{TiC}$ particles and the $\mathrm{FeAl}$ ligaments. The FeAl ligaments can then be considered to be miniature tensile specimens. In order for cleavage to occur, dislocation pileups long enough to generate the ideal cleavage stress (appr. E/10) at the tip of the pile-up are needed. The critical length $\mathrm{L}$ for these pile-ups is determined by the following equation:

$$
\tau_{\mathrm{h}}=\left[\pi(1-\mathrm{v}) \mathrm{L} \tau^{2}\right] /(\mathrm{Gb})=\mathrm{E} / 10
$$

where $\tau$ is the shear stress applied on the ligament, $\mathrm{G}$ the shear modulus, and $\mathrm{b}$ the Burgers vector. With $G=E /[2(1+v)]$, the critical pile-up length for the cleavage fracture of the iron aluminide subjected to a tensile stress $\sigma=2 \tau$ is given by: 

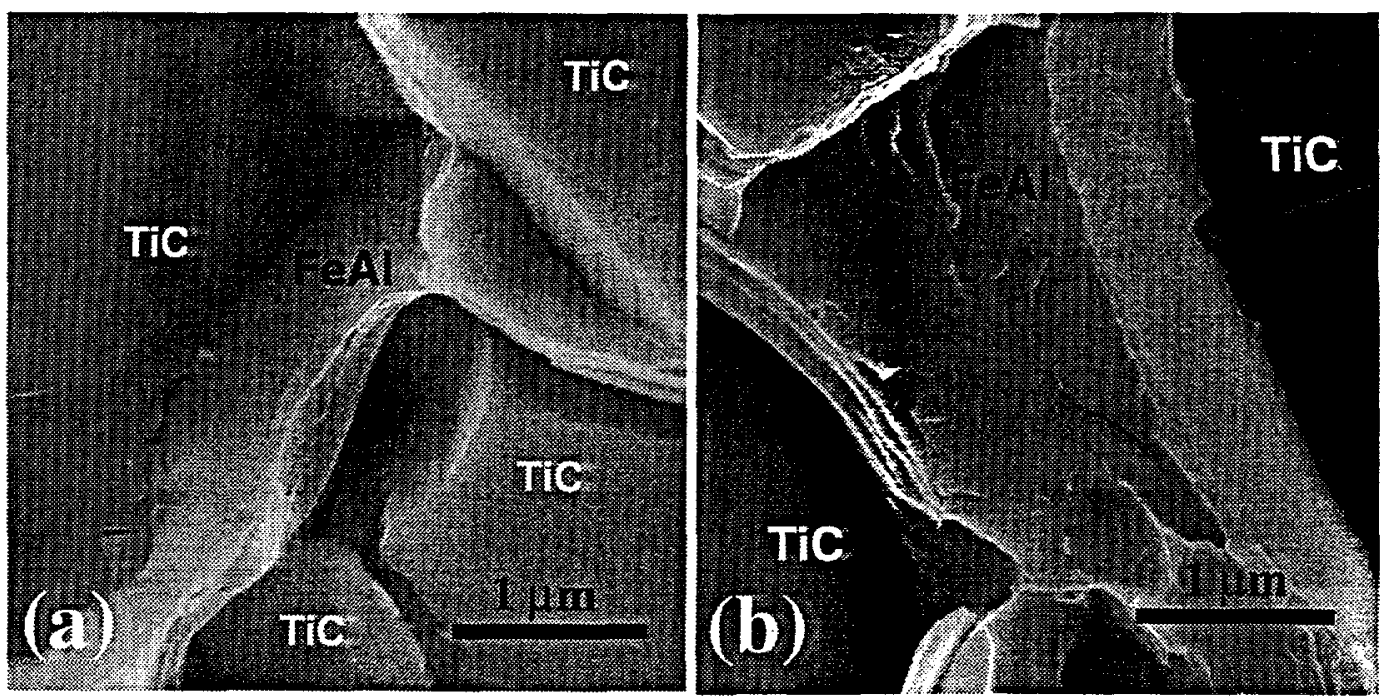

FIG12. A room temperature fracture surface of FeAl/70 vol.\% TiC shows (a) ductile fracture as well as (b) brittle cleavage fracture of the iron aluminide matrix ligaments.

$$
\mathrm{L}=[\mathrm{b} /(5 \pi)](\mathrm{E} / \sigma)^{2} .
$$

With typical values of $E=180 \mathrm{GPa}, b=0.25 \mathrm{~nm}$, and $\sigma=500 \mathrm{MPa}$, the critical pile-up length is calculated to be about $2 \mu \mathrm{m}$, with about 70 dislocations in the pile-up [24]. This agrees reasonably well with the tentative arrest in the toughness decrease in FIG11 and with the size distribution of the fracture modes in FIG13. If the FeAl ligaments are thinner than 1 or $2 \mu \mathrm{m}$, the pile-ups generated in them are simply not long enough to reach the ideal cleavage stress required for the nucleation of cleavage cracks. When the ligaments are thicker than $2 \mu \mathrm{m}$, they are not entirely brittle, but neck down somewhat as shown in FIG12(b). It appears that the pile-ups involved in the necking of these ligaments were sufficiently long to nucleate the cleavage cracks required for failure by cleavage. As discussed in recent work, the mechanism described above may also occur in other intermetallic systems such as $\mathrm{NiAl}-\mathrm{Cr}$ and $\mathrm{Nb}-\mathrm{Si}$ [24].

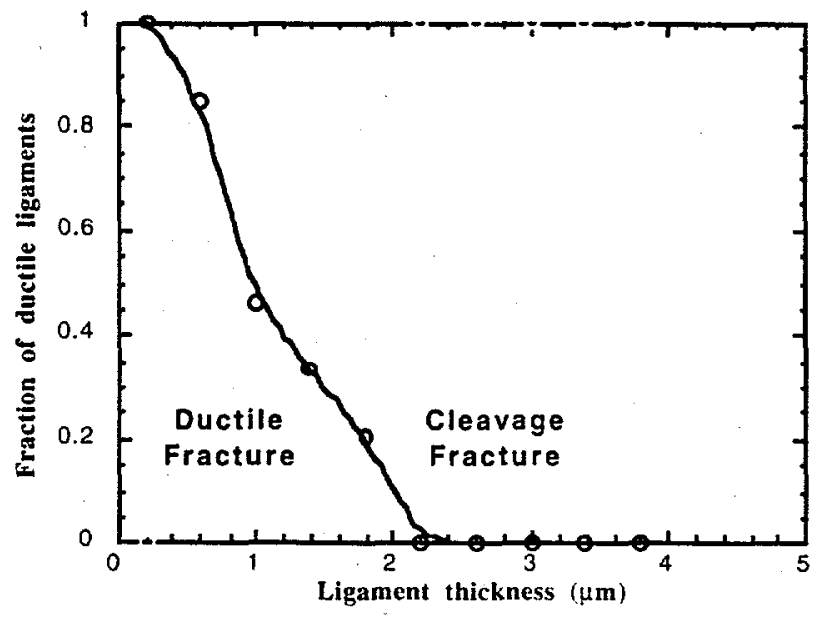

FIG13. The fracture mode of FeAl ligaments in an $\mathrm{FeAl} / 70$ vol.\% $\mathrm{TiC}$ composite depends on the thickness of the ligaments. 
The anticipated toughness increase due to the high ductility of thin FeAl ligaments is not easily verifiable for several reasons. In a given specimen, there is a wide distribution in ligament sizes which tends to smear out the toughness increase. Also, those ligaments above the critical size are not entirely brittle, but do show some necking prior to cleavage fracture. More importantly, the fracture toughness depends inversely on the thickness of the ligaments. As the ceramic volume fraction of the composites is increased, the FeAl ligaments become thinner. The expected increase in the fracture toughness due to the ductility of thin ligaments is offset by the concomitant decrease in the fracture toughness as the ligament thickness decreases.

\section{Elimination of environmental embrittlement}

Environmental embrittlement of iron aluminides by water vapor was discovered in 1989 by Liu, Lee, and McKamey [5]. A vast amount of research on iron aluminides as well as other intermetallics has been carried out since then on this type of environmental embrittlement. The basic idea is that $\mathrm{Al}$ atoms are exposed at the tip of an advancing crack and reduce water vapor according to an equation of the type:

$$
2 \mathrm{Al}+3 \mathrm{H}_{2} \mathrm{O} \rightarrow \mathrm{Al}_{2} \mathrm{O}_{3}+6 \mathrm{H} \text {. }
$$

The common picture is that the atomic hydrogen liberated in this reaction diffuses to the hydrostatic region just ahead of the crack tip and causes hydrogen embrittlement. An immediate consequence of this picture is the time dependence of the embrittlement. The embrittlement is expected to be particulary severe when cracks propagate slowly. Embrittlement can be avoided by propagating the cracks very quickly. This effect has not only been seen in slow crack growth studies [25], but also in tensile tests [8]. At low strain rates, such as $10^{-6} \mathrm{~s}^{-1}$, the fracture strain may only be $2 \%$, while it may reach $10 \%$ at strain rates on the order of $1 \mathrm{~s}^{-1}$. The low fracture strains at low strain rates are thought to be the result of slow crack growth, which takes place at relatively low stress intensity factors. One way to eliminate or alleviate environmental embrittlement is to prevent the ingress of water vapor, for example by oil coatings. The present research offers another possibility: if cracks are prevented from forming in the first place, environmental embrittlement ought not to occur. This hypothesis has been tested by preparing $\mathrm{FeAl} / \mathrm{TiC}$ composites with different volume fractions, and therefore different ligament thicknesses [26]. Chevron-notched specimens were slowly broken in 3-point bending in either water or a dry oxygen environment, and their crack growth resistance was measured. Since the FeAl ligaments thicker than 1 or $2 \mu \mathrm{m}$ are expected to fracture by cleavage, slow crack growth and, associated with it, environmental embrittlement, are expected for such ligaments. Indeed, for average FeAl ligament thicknesses above $1.5 \mu \mathrm{m}$, environmental embrittlement is observed: the crack growth resistance of the specimens tested in water is distinctly lower than that for the specimens tested in dry oxygen (FIG15). Ligaments thinner than $1.5 \mu \mathrm{m}$, on the other hand, are expected to fracture in a ductile manner. They are not expected to form cleavage cracks and are therefore not expected

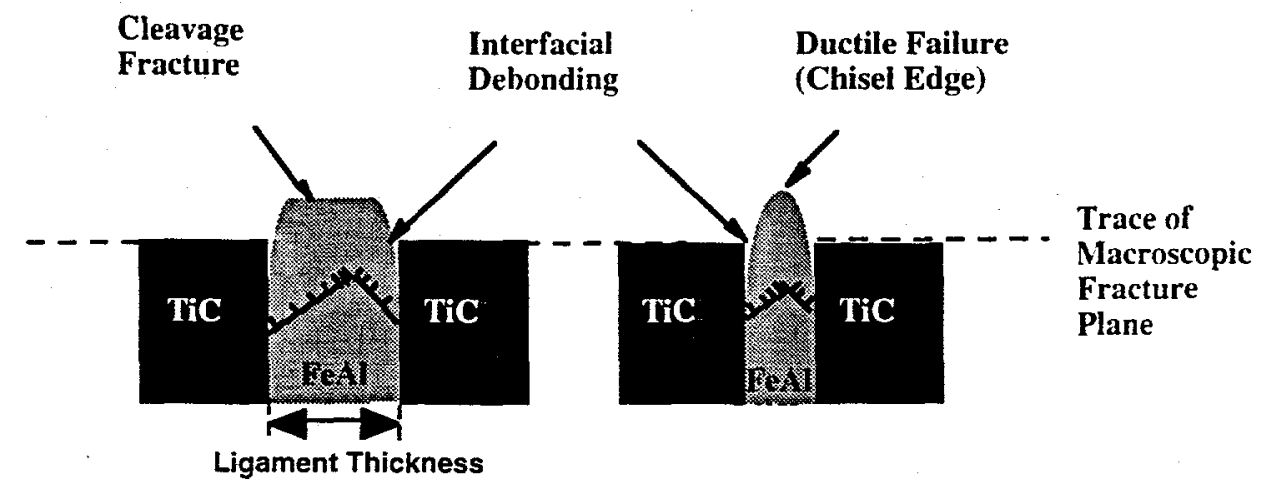

FIG14. Schematic illustration of the brittle-to-ductile size transition for thin FeAl ligments. 
to show environmental embrittlement. FIG15 shows this indeed to be the case. It appears therefore that environmental embrittlement by water vapor is inhibited in iron aluminide composites as long as the iron aluminide matrix occurs in the form of sufficiently thin ligaments.

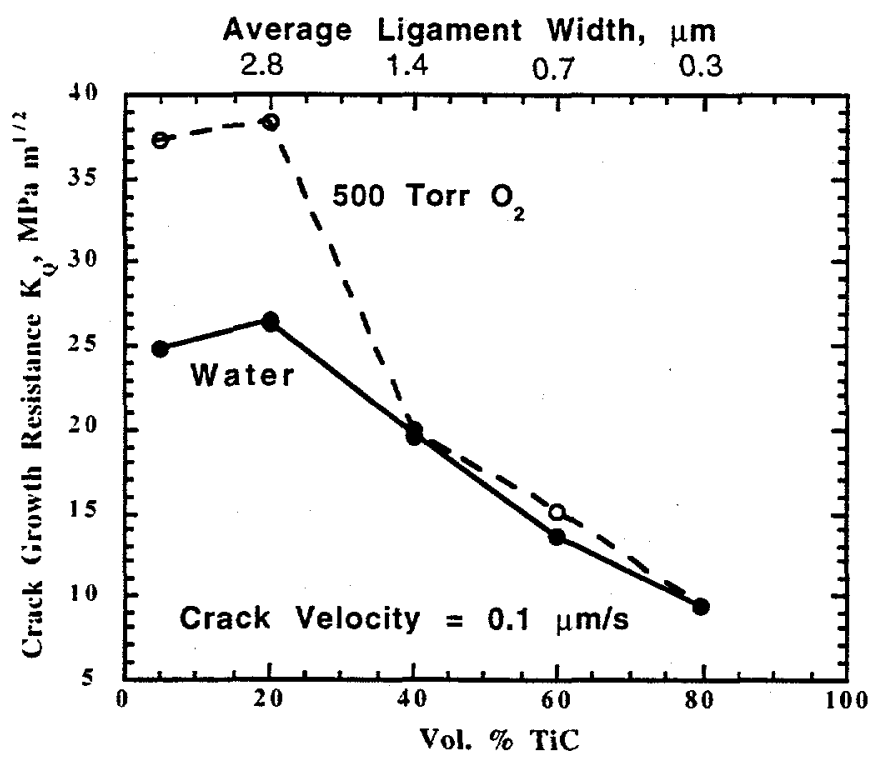

FIG15. Crack growth resistance of $\mathrm{FeAl} / \mathrm{TiC}$ composites with different $\mathrm{FeAl}$ ligament thicknesses, tested in water or dry oxygen, respectively.

\section{CONCLUSIONS}

Strong and tough iron aluminide/ceramic composites may be produced by techniques such as liquid phase sintering of powder mixtures, or pressureless melt infiltration of ceramic powders with liquid FeAl. While progress has been made in the processing of these composites, their microstructures and scatter in mechanical properties suggest that there is room for significant improvements. These would require processing and microalloying with the aim of eliminating pores, oxide inclusions, and of improving the interfacial bonding. While monolithic iron aluminides tend to fracture by cleavage in a brittle manner (unless brittle grain boundary fracture intervenes), the thin $(<1 \mu \mathrm{m})$ ligaments available in iron aluminide composites fracture in a ductile manner. For a variety of reasons, this brittle-to-ductile size transition does not significantly improve the fracture toughness of the composites. However, the absence of cleavage cracks in the thin ligaments means that slow crack growth cannot occur. Since hydrogen embrittlement associated with slow crack growth is thought to be the mechanism responsible for environmental embrittlement of iron aluminides in water vapor, this environmental embrittlement is not observed in iron aluminide composites with sufficiently small ligament sizes.

\section{ACKNOWLEDGEMENT}

This research was sponsored by the Division of Materials Sciences, U.S. Department of Energy under contract number DE-AC05-96OR22464 with Lockheed Martin Energy Research Corporation. The review of this manuscript by C. G. McKamey and J. A. Horton is appreciated.

\section{REFERENCES}

1. Processing, Properties, and Applications of Iron Aluminides, J. H. Schneibel and M. A. Crimp. eds., TMS, Warrendale, PA (1994).

2. Intemational Symposium on Nickel and Iron Aluminides: Processing, Properties, and Applications, S. C. Deevi, V. K. Sikka, P. J. Maziasz, and R. W. Cahn, eds.. ASM, Materials Park, OH (1997).

3. M. R. Hajaligol, S. C. Deevi, V. K. Sikka, C. R. Scorey, accepted for publication in Proceeedings of International Symposium on Iron Aluminides: Alloy Design. Processing, Properties \& Applications, to appear in Materials Science and Engineering A. 
4. I. Baker and P. R. Munroe, International Materials Reviews 42, 181 (1997).

5. C. T. Liu, E. H. Lee, and C. G. McKamey, Scr. Metall. 23, 875 (1989).

6. C. T. Liu and E. P. George, Scr. Metall. Mater. 24, 1285 (1990).

7. R. J. Lynch, K. A. Gee, and L. A. Heldt, Scr. Metall. Mater. 30, 945 (1994).

8. P. Nagpal and I. Baker, Scr. Metall. Mater. 25, 2577 (1991).

9. J. D. Whittenberger, Mater. Sci. Eng. 77, 103 (1986).

10. R. Subramanian, C. G. McKamey, J. H. Schneibel, L. R. Buck, and P. A. Menchhofer, Mater. Sci. Eng. A254, 119 (1998).

11. K. P. Plucknett, P. F. Becher, and R. Subramanian, J. Mater. Res. 12, 2515 (1997).

12. P. F. Becher and K. P. Plucknett, J. European Ceramic Society 18, 395 (1997).

13. J. H. Schneibel and P. F. Becher, Iron and Nickel Aluminide Composites, in print, J. of the Chinese Institute of Engineers.

14. J. H. Schneibel, C. A. Carmichael, E. D. Specht, and R. Subramanian, Intermetallics 5, 61 (1997).

15. M. K. Inoue, K. Suganuma, and K. Niihara, in High-Temperature Ordered Intermetallic Alloys VII, MRS Symposium Proceedings, Koch et al., eds., MRS, Pittsburgh, PA, Vol. 460, pp. $755-59$ (1997).

16. M. Inoue, H. Nagao, K. Suganuma, K. Niihara, accepted for publication in Proceeedings of Intemational Symposium on Iron Aluminides: Alloy Design, Processing, Properties \& Applications, to appear in Materials Science and Engineering A.

17. K. S. Ravichandran, Acta Metall. Mater. 42, 1113 (1994).

18. J. H. Schneibel and R. Subramanian, in 1996 World Congress on Powder Metallurgy \& Particulate Materials, Metal Powder Industries Federation, Vol. 5, pp. 16-167 to 16-175 (1996).

19. R. Subramanian and J. H. Schneibel, Mater. Sci. Eng. A239-240, 633 (1997).

20. R. Subramanian and J. H. Schneibel, Intermetallics 5, 401 (1997).

21. A. F. Guillermet, Metall. Trans. A 20A, 935 (1989).

22. R. Subramanian and J. H. Schneibel, Mater. Sci. Eng. A244, 103 (1998).

23. J. H. Schneibel and R. Subramanian, in Boundaries and Interfaces in Materials: The David A. Smith Symposium, R. C. Pond, W. A. T. Clark, A. H. King, and D. B. Williams, eds., TMS, Warrendale, PA, pp. 315-321 (1998).

24. R. Subramanian and J. H. Schneibel, Acta Mater. 46, 4733 (1998).

25. J. H. Schneibel and E. D. Specht, Scr. Metall. Mater 31, 1737 (1994).

26. R. Subramanian and J. H. Schneibel, Mater. Sci. Eng. A239-240, 633 (1997). 